\title{
Impact of glycaemic and lipid control on outcome after percutaneous coronary interventions in diabetic patients
}

\author{
C Briguori, G Condorelli, F Airoldi, G W Mikhail, B Ricciardelli, A Colombo
}

Heart 2004;90:1481-1482. doi: 10.1136/hrt.2003.030437

$\mathrm{P}$

atients with type 2 diabetes mellitus account for approximately $20 \%$ of patients undergoing percutaneous coronary interventions (PCI). PCI is less effective in diabetic than in non-diabetic patients. ${ }^{12}$ Glycaemic and lipid control may have an impact on the clinical outcome in type 2 diabetic patients following elective PCI.

\section{METHODS}

From January 2000 to June 2001, 280 consecutive patients with type 2 diabetes mellitus successfully underwent their first elective PCI at one of our institutions. Optimal metabolic control was defined as a glycosylated haemoglobin (HbAlc) concentration of $<7.0 \%$ and a low density lipoprotein cholesterol (LDL-C) concentration $<100 \mathrm{mg} / \mathrm{d}(<2.6 \mathrm{mmol} / \mathrm{l})$. Three groups were identified: (1) optimal group ( $\mathrm{n}=45,16 \%$ of patients) with optimal glycaemic and lipid control; (2) suboptimal group ( $\mathrm{n}=126,45 \%$ of patients) with only one target value reached; (3) poorly controlled group ( $\mathrm{n}=109$, $39 \%$ of patients) who failed to reach either glycaemic or lipid target values. The end point of the study was the rate of major adverse cardiovascular events (MACE), defined as death of any cause, non-fatal myocardial infarction, and target vessel revascularisation, at 12 months in the three groups of patients. All patients received aspirin (325 mg daily, indefinitely) and ticlopidine (250 mg twice daily, for at least 30 days) or clopidogrel ( $75 \mathrm{mg}$ daily, for at least 30 days). Glycoprotein IIb/IIIa inhibitors were administered according to operator discretion.

\section{RESULTS}

Clinical, angiographic, and procedural characteristics are summarised in table 1. At mean (SD) 12 (4) months, MACE occurred in $6(13.3 \%)$ patients in the optimal group, in $40(32 \%)$ patients in the sub optimal group, and in 55 $(50.5 \%)$ patients in the poorly controlled group $(\mathrm{p}<0.001)$. Variables entered into the Cox regression analysis were: age $\geqslant 70$ years, sex, insulin treatment, statin treatment, nephropathy, optimal glycaemic and lipid control, small vessel, elective glycoprotein IIb/IIIa inhibitors, left ventricular ejection fraction $<40 \%$, complete revascularisation, and multivessel PCI. The independent predictors of MACE at follow up were: insulin treatment (hazard ratio (HR) 3.43, $95 \%$ confidence interval $(\mathrm{CI}) 1.59$ to $7.42 ; \mathrm{p}=0.002)$, optimal group (HR 0.29, 95\% CI 0.09 to $0.97 ; \mathrm{p}=0.045$ ), and age $\geqslant 70$ years (HR 2.10, 95\% CI 1.10 to $4.25 ; \mathrm{p}=0.045$ ).

\section{DISCUSSION}

We showed that an HbAlc concentration of $<7 \%$ and an LDL-C concentration of $<100 \mathrm{mg} / \mathrm{dl}$ favourably influenced the outcome in diabetic patients after PCI. A very low event rate was observed in patients with both a strict glycaemic and blood lipid control. Our study highlights shortcomings in the effectiveness of treatment and prevention of risk factors that are associated with high morbidity and mortality. It may be that a stricter surveillance, a better lifestyle, and a more aggressive pharmacological approach would allow us to improve metabolic control. ${ }^{3}$ The present study was not a randomised controlled
Table 1 Patient characteristics according to glycaemic and lipid control

\begin{tabular}{|c|c|c|c|c|}
\hline & $\begin{array}{l}\text { Optimal } \\
\text { group } \\
(n=45)\end{array}$ & $\begin{array}{l}\text { Suboptimal } \\
\text { group } \\
(n=126)\end{array}$ & $\begin{array}{l}\text { Poorly } \\
\text { controlled } \\
\text { group } \\
(n=109)\end{array}$ & p Value \\
\hline Age (years) & $63(7)$ & $62(9)$ & $62(10)$ & 0.67 \\
\hline Male & $39(87 \%)$ & $104(82.5 \%)$ & $74(68 \%)$ & 0.008 \\
\hline Unstable angina & $7(16 \%)$ & 23 (18\%) & $26(24 \%)$ & 0.63 \\
\hline $\begin{array}{l}\text { Diabetes treatment } \\
\text { Non-insulin } \\
\text { requiring* } \\
\text { Insulin requiring } \dagger\end{array}$ & $\begin{array}{l}36(80 \%) \\
9(20 \%)\end{array}$ & $\begin{array}{l}102(81 \%) \\
24(19 \%)\end{array}$ & $\begin{array}{l}80(73 \%) \\
29(27 \%)\end{array}$ & 0.33 \\
\hline Statin treatment & $35(78 \%)$ & $83(66 \%)$ & $66(61 \%)$ & 0.14 \\
\hline $\mathrm{HbAlc}(\%)$ & $6.1(0.6)$ & $7.2(1.4)$ & $8.5(1.3)$ & $<0.001$ \\
\hline LDL-C (mmol/l)‡ & $2.05(0.42)$ & $2.63(0.80)$ & $3.56(0.68)$ & $<0.001$ \\
\hline $\begin{array}{l}\text { Left ventricular } \\
\text { ejection fraction (\%) }\end{array}$ & $58(12)$ & $57(11)$ & $57(9)$ & 0.75 \\
\hline $\begin{array}{l}\text { Previous myocardial } \\
\text { infarction }\end{array}$ & $25(56 \%)$ & $65(52 \%)$ & $50(46 \%)$ & 0.58 \\
\hline $\begin{array}{l}\text { Previous bypass } \\
\text { surgery }\end{array}$ & $4(9 \%)$ & $20(16 \%)$ & $10(9 \%)$ & 0.34 \\
\hline Systemic hypertension & $33(73 \%)$ & $84(67 \%)$ & $81(74 \%)$ & 0.31 \\
\hline Smoker & $21(47 \%)$ & $69(55 \%)$ & $40(37 \%)$ & 0.025 \\
\hline Nephropathy & $18(40 \%)$ & $54(43 \%)$ & $54(50 \%)$ & 0.51 \\
\hline \multicolumn{5}{|l|}{$\begin{array}{l}\text { Distribution of coronary } \\
\text { artery disease }\end{array}$} \\
\hline Single vessel & $19(42 \%)$ & $35(28 \%)$ & $34(31 \%)$ & 0.090 \\
\hline Double vessel & $19(42 \%)$ & $51(40.5 \%)$ & $36(33 \%)$ & \\
\hline Triple vessel & $7(16 \%)$ & $40(31.5 \%)$ & $39(36 \%)$ & \\
\hline $\begin{array}{l}\text { Number of treated } \\
\text { vessels/patient }\end{array}$ & $1.3(0.5)$ & $1.3(0.5)$ & $1.3(0.5)$ & 0.96 \\
\hline $\begin{array}{l}\text { Number of treated } \\
\text { lesions/patient }\end{array}$ & $1.6(0.8)$ & $1.5(0.7)$ & $1.6(0.9)$ & 0.49 \\
\hline \multicolumn{5}{|l|}{ Diameter stenosis (\%) } \\
\hline Pre- & $83(13)$ & $82(16)$ & $79(15)$ & 0.22 \\
\hline $\begin{array}{l}\text { Post- } \\
\text { Reference vessel } \\
\text { diameter }(\mathrm{mm})\end{array}$ & $6(10)$ & $5(9)$ & $8(14)$ & 0.12 \\
\hline Pre- & $2.91(0.58)$ & $2.88(0.60)$ & $2.95(0.59)$ & 0.37 \\
\hline Post- & $3.04(0.61)$ & $3.05(0.61)$ & $3.08(0.64)$ & 0.71 \\
\hline Lesion length $(\mathrm{mm})$ & $11(5)$ & $11(5)$ & $11(4)$ & 0.75 \\
\hline $\begin{array}{l}\text { Complete } \\
\text { revascularisation }\end{array}$ & $22(49 \%)$ & $59(47 \%)$ & $55(50.5 \%)$ & 0.57 \\
\hline $\begin{array}{l}\text { Type of PCI } \\
\text { Balloon only }\end{array}$ & $4(9 \%)$ & $11(9 \%)$ & $11(10 \%)$ & 0.93 \\
\hline Bare metal stent & $41(91 \%)$ & 115 (91\%) & $98(90 \%)$ & \\
\hline $\begin{array}{l}\text { Elective glycoprotein } \\
\text { llb/Illa inhibitors }\end{array}$ & $17(38 \%)$ & $46(37 \%)$ & $44(41 \%)$ & 0.79 \\
\hline
\end{tabular}

*Non-insulin requiring which includes patients treated with diet and oral hypoglycaemic drugs but no insulin.

tInsulin requiring which includes patients treated with insulin, regardless of other treatment.

‡To convert values of LDL-C to $\mathrm{mg} / \mathrm{dl}$, divide by 0.026 .

trial. We cannot therefore exclude the fact that patients with poorer glycaemic and lipid profiles were in a more advanced stage of coronary atherosclerosis. Furthermore, the potential impact of glycoprotein IIb/IIIa antagonists and statins may not be apparent as the study was not powered to address this.

Abbreviations: $\mathrm{HbAlc}$, glycosylated haemoglobin; LDL-C, low density lipoprotein cholesterol; MACE, major adverse cardiovascular events; $\mathrm{PCl}$, percutaneous coronary intervention 


\section{Authors' affiliations}

C Briguori* , B Ricciardelli, Laboratory of Interventional Cardiology,

Clinica Mediterranea, Naples, Italy

F Airoldi, G W Mikhail, A Colombo, San Raffaele Hospital, Milan, Italy

G Condorelli, Department of Biology, Cellular and Molecular Pathology,

"Federico II" University, Naples, Italy

*Also at San Raffaele Hospital, Milan, Italy

Correspondence to: Dr Carlo Briguori, Interventional Cardiology, Clinica Mediterranea, Via Orazio 2, I-80121, Naples, Italy; briguori.carlo@hsr.it

Accepted 16 February 2004

\section{REFERENCES}

1 Stein B, Weintraub W, King S. Influence of diabetes mellitus on early and late outcome after percutaneous transluminal coronary angioplasty. Circulation 1995:91:979-89.

2 Abizaid A, Kornowski R, Mintz G, et al. The influence of diabetes mellitus on acute and late clinical outcomes following coronary stent implantation. J Am Coll Cardiol 1998;32:584-9.

3 Gæde $\mathbf{P}$, Vedel $\mathrm{P}$, Larsen $\mathrm{N}$, et al. Multifactorial intervention and cardiovascular disease in patients with type 2 diabetes. N Engl J Med 2003;348:383-93.

4 Corpus RA, George PB, House JA, et al. Optimal glycemic control is associated with a lower rate of target vessel revascularization in treated type II diabetic patients undergoing elective percutaneous coronary intervention. J Am Coll Cardiol 2004;43:8-14.

\section{IMAGES IN CARDIOLOGY}

\section{Late thrombotic occlusion of paclitaxel eluting stent more than one year after stent implantation}

U se of drug eluting stents has become the state-of-the-art therapy for percutaneous treatment of obstructive coronary artery disease. However, concern has been expressed on the delayed healing after implantation of a drug eluting stent. We present the first report of late thrombotic occlusion of a paclitaxel eluting stent (Taxus, Boston Scientific Corp) at just more than one year after implantation.

A 44 year old Indian man underwent implantation of a $3.0 / 24 \mathrm{~mm}$ paclitaxel eluting stent on 27 September 2002 for treatment of unstable angina caused by proximal left anterior descending (LAD) artery stenosis. Long term aspirin and six months of clopidogrel were prescribed, together with anti-lipid treatment. The patient was compliant but continued to smoke. He remained well until 8 October 2003 when he presented with chest pain for three hours, associated with diaphoresis. A 12 lead ECG showed ST segment elevation consistent with acute anterior myocardial infarction. Emergency coronary angiography confirmed a totally occluded proximal LAD artery, the site of the paclitaxel eluting stent (panel A). The occlusion was crossed using a 0.014 inch floppy guidewire, with immediate restoration of antegrade TIMI grade 2 flow. Heavy thrombus burden was noted in-stent. A PercuSurge Export aspiration catheter was used to aspirate the thrombus (lower left panel). Intravascular ultrasound (lower right panel) showed only mild in-stent neointimal hyperplasia, suggesting primarily a thrombotic event. The stent was well expanded except for a small segment at the proximal stent edge. No stent malapposition or edge stenosis was noted. A 3.0/10 mm cutting balloon, and then a $3.25 / 15 \mathrm{~mm}$ NC monorail balloon was used to dilate the stent in sequence. The procedure was performed with the support of double bolus intracoronary doses of eptifibatide, given 10 minutes apart, followed by continuous intravenous infusion for 48 hours. Final angiography (panel B) showed $<10 \%$ residual stenosis, TIMI 3 flow and myocardial blush grade 3

C H Lee

H C Tan H Y Ong

S G Teo Y T Lim

mdclimył@nus.edu.sg
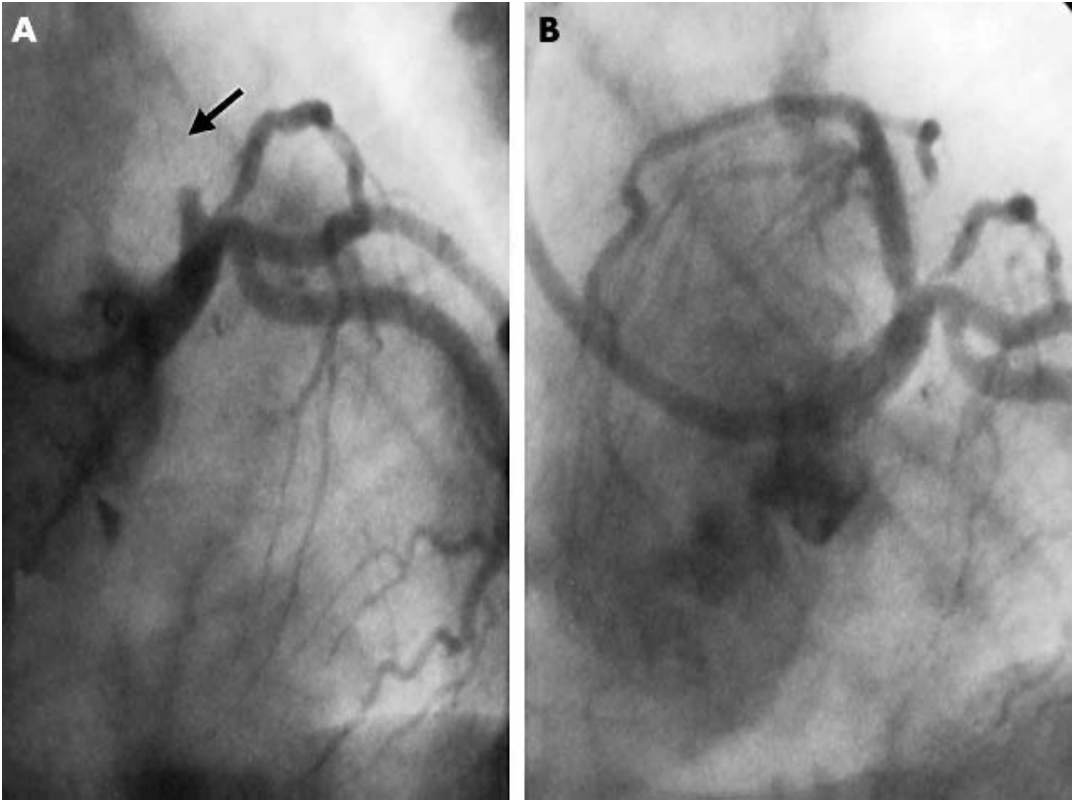

(A) Diagnostic angiography showed total occlusion of the paclitaxel eluting stent (arrow). (B) Final angiography after thrombus aspiration and balloon dilatation of the stent showed normal antegrade flow (TIMI 3).

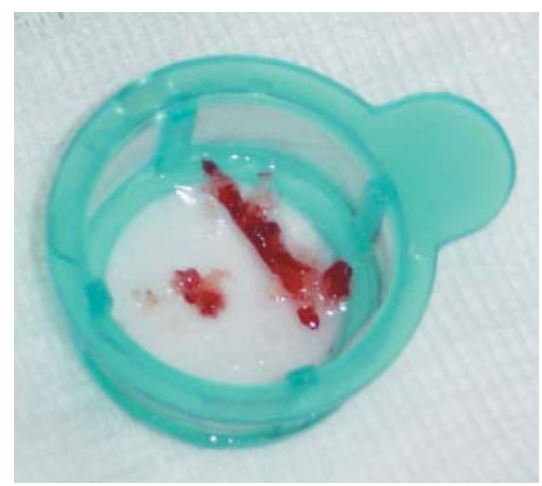

Thrombus aspirated by the PercuSurge Export aspiration catheter.

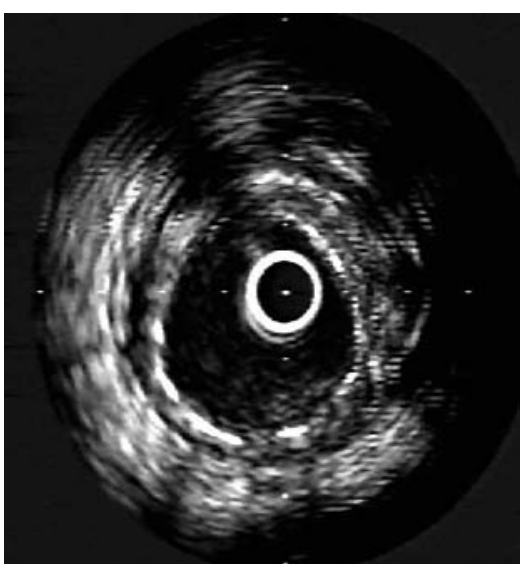

Intravascular ultrasound image of the stent after thrombus aspiration. The stent was well expanded and apposed. No significant in-stent neointimal hyperplasia was detected. 